\title{
Simulation of DTC-CBSVPWM fed SPMSM Drive with Five-level Diode Clamped Inverter
}

\author{
G. Sree Lakshmi \\ Research Scholar, \\ Dept. of EEE, CVR College of \\ Engineering, Hyderabad, India
}

\author{
S. Kamakshaiah \\ Former Professor \& Head, \\ Department of EEE, JNT \\ University, Hyderabad, India
}

\author{
G. Tulasi Ram Das \\ Vice-Chancellor, \\ JNT University, \\ Kakinada, India
}

\begin{abstract}
In this paper a simulation analysis of DTC-CBSVPWM of SPMSM drive using five-level diode clamped inverter is analyzed. It has simple structure and provides dynamic behavior comparable with classical DTC. Direct Torque Control (DTC) is an accurate controller for permanent magnet synchronous motor (PMSM) due to its robust and fast torque response in steady-state and transient operating condition. However, the main disadvantage of DTC is high ripples in stator current, flux linkage and torque due to the application of same active voltage vector during the whole sample period and possibly several consecutive sample intervals. This can be overcome by using proper modulation technique. Space Vector Modulation (SVM) which synthesizes any voltage vector lying inside the sextant gives good performance, but however the complexity involved is more in calculating angle and sector. To reduce the complexity involved in SVPWM, a novel modulation technique named Unified voltage modulation or carrier based space vector pulse width modulation (CBSVPWM) is described using the concept of effective time. By using this method the inverter output voltage is directly synthesized by the effective times and the voltage modulation task can be greatly simplified. The actual gating signals for each inverter arm can be easily deduced as a simple form using the effective time relocation algorithm.
\end{abstract}

\section{Keywords}

DTC-CBSVPWM, SPMSM, Five-Level Diode Clamped Inverter.

\section{INTRODUCTION}

Permanent magnet synchronous motors are replacing DC and Induction motors in high performance drives due to their several advantages such as low inertia, high efficiency, high power density and good reliability. They also find increased application in robotics, ships, windmills, compressors, pumps, fans and in vehicle drives. PMSM with small size and robustness is possible due to the development of new rareearth magnetic materials like Neodymium Iron Boron $\left(\mathrm{Nd}_{2} \mathrm{Fe}_{14} \mathrm{~B}\right)$ and Samarium Cobalt $\left(\mathrm{SmCo}_{5}, \mathrm{Sm}_{2} \mathrm{Co}_{17}\right)$ which have high energy density and high resistance for demagnetization. PMSM are classified into two types, Brushless DC motors (BLDC) and PMAC. Sinusoidal PMAC machines are further classified into two groups with respect to their rotor structures as; Surface Mount Permanent Magnet (SMPM) synchronous motors and Interior Permanent Magnet (IPM) synchronous motors. IPM motors have the permanent magnets buried in the rotor core and SMPM motors have the permanent magnets mounted on the outer surface of the rotor. The reluctance variation between the direct and quadrature axes is fairly small in SPMSM. Accordingly, there is very little variation between the quadrature and direct axes inductances. This particular fact has consequence on the control operation, and characteristics of the surface mount PMSM drives. With respect to air-gap torque, IPM is better all the time compared to SMPM machines but with respect to speed range availability when the same voltage is considered, the SMPM is better compared to IPM machines. However, if the air gap power is considered, the SMPM is better in almost all the ranges compared to IPM [1][2].

Vector control is the most important, efficient and simple method to control the PMSM, which can be divided into two types. Field Oriented Control (FOC) and Direct Torque Control (DTC). In FOC, the main objective is to control the current vector and in DTC the main objective is to control the torque producing flux vector. In the middle of 1980's Depenbrock and Takahashi was initially proposed Direct Torque Control (DTC) for induction machines and in the late 1990 French and Zhong which was then applied to PMSM [3]-[5]. The direct torque control (DTC) is an accurate controller for permanent magnet synchronous motor (PMSM) which is based on decoupled control of flux and torque which achieves robust and fast torque response in steady-state and transient operating condition, without the need of speed or position sensors, current regulator, coordinate transformation and PWM signal generator. The principle is based on the selection of voltage vectors from the difference between reference and actual value of torque and flux linkages [6]-[8]. The torque and flux errors are compared in hysteresis comparators. Although DTC has many advantages over current control, it has still some disadvantages such as high current ripples, variable switching frequency and difficulty in controlling torque and flux at very low [9]-[12]. In recent years, this can be overcome with the development of multilevel inverter proposed by Vas and Martins, a smoother torque can be expected with more voltage space vectors available to control flux and torque[13]-[15]. However, more power devices are needed to achieve a lower ripple and almost constant switching frequency. This can be obtained by using proper modulation techniques. Modified DTC schemes with constant switching frequency and low torque ripple were reported by others, where space vector modulation (SVM) is incorporated with DTC, to provide a constant inverter switching frequency. SVPWM gives good performance, but however the complexity involved is more in calculating angle and sector. To reduce the complexity involved in SVPWM, a novel modulation technique named Unified voltage modulation or carrier based space vector pulse width modulation (CBSVPWM) is described using the concept of effective. By using this method the inverter output voltage is directly by the effective times and the voltage modulation task can be greatly simplified [19]-[22]. The actual gating signals for each inverter arm can be easily deduced as a simple form using the effective time relocation algorithm. In this paper a DTC-CBSVPWM is analyzed with surface-mounted permanent magnet synchronous motor and the torque and speed response is studied by using five-level diode clamped inverter [16]-[18]. 


\section{SPMSM MODELLING}

In surface mounted permanent magnet each of the permanent magnet is mounted on the surface of the rotor, making it easy to build, and specially skewed poles are easily magnetized to minimize cogging torque. These motors are considered to have small saliency, thus having practically equal inductances in both axes. The permeability of the permanent magnet is almost that of the air, thus the magnetic material becoming an extension of the air gap.

The direct and quadrature axes winding inductances are equal and given as $\mathrm{L}_{\mathrm{s}}$. The voltage, current, and stator flux linkage phasors in the rotor reference frames as the result of their $\mathrm{d}$ and q-axes components are defined as

$\mathrm{V}_{\mathrm{S}}^{\mathrm{R}}=\mathrm{V}_{\mathrm{QS}}^{\mathrm{R}}-\mathrm{j} \mathrm{V}_{\mathrm{DS}}^{\mathrm{R}}$

$\mathrm{I}_{\mathrm{S}}^{\mathrm{R}}=\mathrm{I}_{\mathrm{QS}}^{\mathrm{R}}-\mathrm{jI} \mathrm{I}_{\mathrm{DS}}^{\mathrm{R}}$

$\lambda_{\mathrm{S}}^{\mathrm{R}}=$

$\lambda_{\mathrm{QS}}^{\mathrm{R}}-\mathrm{j} \lambda_{\mathrm{DS}}^{\mathrm{R}}$

The stator voltage equation for the PMSM with surface mount magnets is given as

$V_{S}^{R}=\left(R_{S}+L_{S} p\right) I_{S}^{R}+j \omega_{R} \lambda_{S}^{R}$

The flux linkages in $\mathrm{d}$ - and q-axes is given as

$\lambda_{\mathrm{QS}}^{\mathrm{R}}=\mathrm{L}_{\mathrm{S}} \mathrm{I}_{\mathrm{QS}}^{\mathrm{R}}$

$\lambda_{\mathrm{DS}}^{\mathrm{R}}=\mathrm{L}_{\mathrm{S}} \mathrm{I}_{\mathrm{DS}}^{\mathrm{R}}+\lambda_{\mathrm{AF}}$

Now the stator current phasor is derived as

$\mathrm{I}_{\mathrm{S}}^{\mathrm{R}}=\frac{\lambda_{\mathrm{S}}^{\mathrm{R}}+\mathrm{j} \lambda_{\mathrm{AF}}}{\mathrm{L}_{\mathrm{S}}}$

Now substituting these in the voltage equation and assuming that the variation in the rotor flux linkages with time is to be zero, then the resulting stator voltage phasor is

$\mathrm{V}_{\mathrm{S}}^{\mathrm{R}}=\left[\mathrm{p}+\frac{1}{\tau_{\mathrm{S}}}+\mathrm{j} \omega_{\mathrm{R}}\right] \lambda_{\mathrm{S}}^{\mathrm{R}}+\mathrm{j} \frac{\lambda_{\mathrm{AF}}}{\tau_{\mathrm{S}}}$

The electromagnetic torque is given as

$\mathrm{T}_{\mathrm{E}}=\frac{3}{3} \frac{\mathrm{p}}{2} \mathrm{I}_{\mathrm{m}}\left[\lambda_{\mathrm{S}}^{\mathrm{R}^{*}} \mathrm{I}_{\mathrm{S}}^{\mathrm{R}}\right]$

$\mathrm{I}_{\mathrm{m}}$ indicates the imaginary part and the asterisk, the conjugate of that variable. The load equation finally is given as

$$
\omega_{R}(s)=\frac{1}{\left(1+s \tau_{m}\right)} \frac{P}{2} \frac{1}{B}\left[\frac{3}{2} \frac{P}{2} I_{m}\left\{\lambda_{S}^{R^{*}} I_{S}^{R}\right\}-T_{L}\right]
$$

\section{DTC OF SPMSM}

The basic principle of Direct Torque Control (DTC) is to estimate the torque and flux errors from hysteresis comparators and to directly select voltage vectors based on the differences between reference and actual value of torque and flux linkage. Advantages of DTC are low complexity, low computational power, and good dynamic performance. The basic idea is to control the stator flux vector in amplitude and angular position. Let $\lambda_{\mathrm{S}}$ be the stator flux linkage vector and $\lambda_{\mathrm{R}}$ be the rotor flux linkage vector in $\mathrm{d}-\mathrm{q}$ coordinate as shown in Fig. 1 Let $\delta$ be the load angle or torque angle between the stator and rotor flux linkages.

The PMSM stator flux linkage and electromagnetic torque equations in the d-q coordinate are follows:

$\lambda_{\mathrm{D}}=\mathrm{L}_{\mathrm{D}} \mathrm{I}_{\mathrm{D}}+\lambda_{\mathrm{R}}$

$$
\begin{aligned}
& \lambda_{\mathrm{Q}}=\mathrm{L}_{\mathrm{Q}} \mathrm{I}_{\mathrm{Q}} \\
& \lambda_{\mathrm{S}}=\sqrt{\lambda_{\mathrm{D}}^{2}+\lambda_{\mathrm{Q}}^{2}} \\
& \mathrm{~T}_{\mathrm{EM}}=\frac{3}{2} \mathrm{p}\left(\lambda_{\mathrm{D}} \mathrm{I}_{\mathrm{Q}}-\lambda_{\mathrm{Q}} \mathrm{I}_{\mathrm{D}}\right)
\end{aligned}
$$

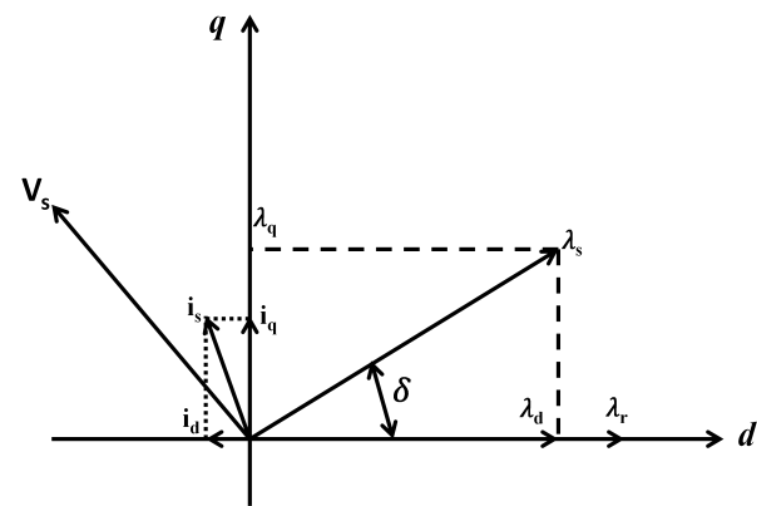

Fig.1 Phasor diagram of flux linkages in d-q frame

Where $\mathrm{p}=$ pole pairs of the motor. The $\mathrm{d}-\mathrm{q}$ current and flux linkage equation can be written as

$\mathrm{I}_{\mathrm{D}}=\frac{\lambda_{\mathrm{D}}-\lambda_{\mathrm{R}}}{\mathrm{L}_{\mathrm{D}}}$

$\mathrm{I}_{\mathrm{Q}}=\frac{\lambda_{\mathrm{D}}}{\mathrm{L}_{\mathrm{Q}}}$

$\lambda_{\mathrm{D}}=\lambda_{\mathrm{S}} \cos \delta$

$\lambda_{\mathrm{Q}}=\lambda_{\mathrm{S}} \sin \delta$

Substituting the above equations in the torque expression

$\mathrm{T}_{\mathrm{EM}}=\frac{3}{2} \mathrm{p} \cdot \frac{\left|\lambda_{S}\right|}{2 \mathrm{~L}_{\mathrm{D}} \mathrm{L}_{\mathrm{Q}}}\left[2 \lambda_{\mathrm{R}} \mathrm{L}_{\mathrm{Q}} \sin \delta-\left|\lambda_{\mathrm{S}}\right|\left(\mathrm{L}_{\mathrm{Q}}-\mathrm{L}_{\mathrm{D}}\right) \sin 2 \delta\right]$

The main disadvantage of conventional DTC is high ripple levels in stator current, flux linkage and torque, due to the application of same active voltage vector during the whole sample period and possibly several consecutive sample intervals. This can be overcome by using proper modulation technique which is a Space Vector Modulation (SVM) which synthesizes any voltage vector lying inside the sextant. In DTC-SVM the hysteresis comparators are replaced by an estimator which calculates an appropriate voltage vector to compensate for torque and flux errors. It gives good dynamic performance with less torque and flux ripple but introduces more complexity and lose an essential feature of DTC, its simplicity. To reduce the complexity involved in SVPWM, a novel modulation technique named Unified voltage modulation or carrier based space vector pulse width modulation (CBSVPWM) is described using the concept of effective time. By using this method the inverter output voltage is directly synthesized by the effective times and the voltage modulation task can be greatly simplified. The actual gating signals for each inverter arm can be easily deduced as a simple form using the effective time relocation algorithm. 


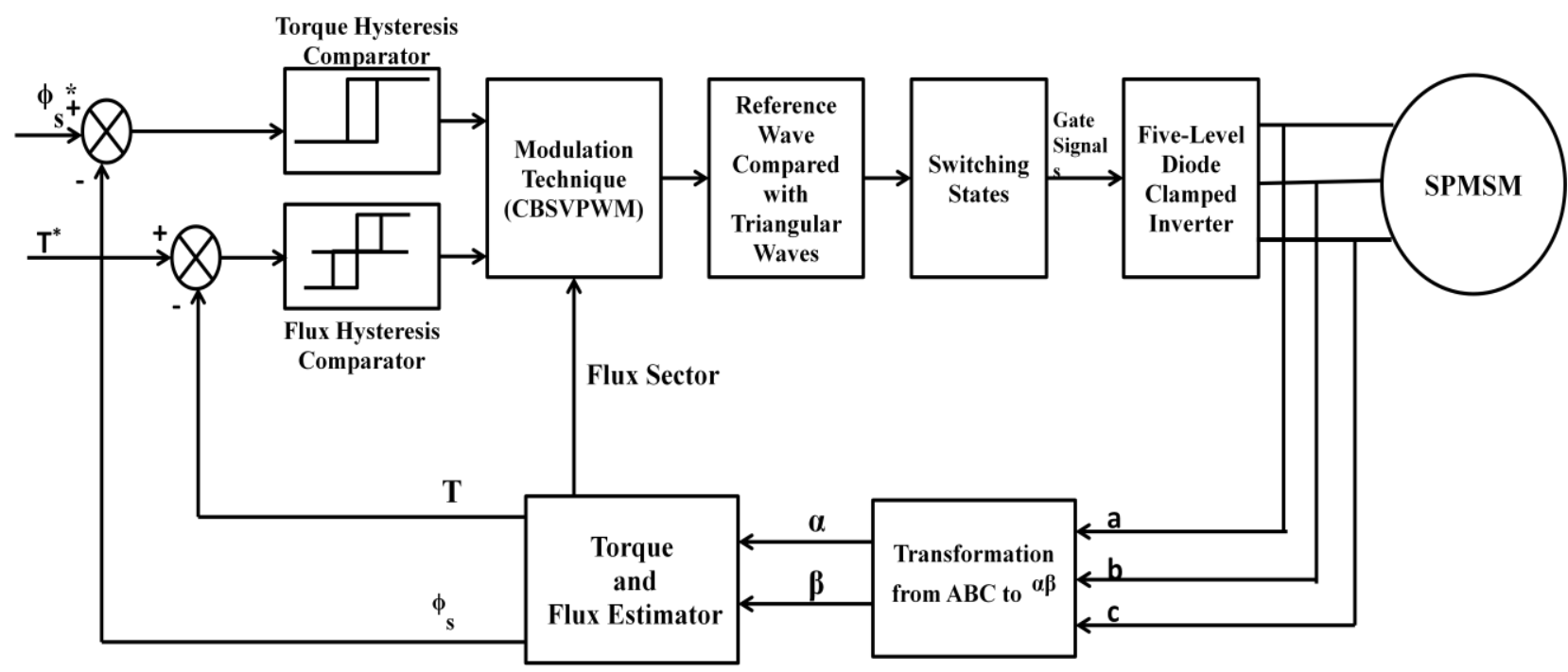

Fig.2 Block diagram of DTC-CBSVPWM fed SPMSM drive using Five-level Diode Clamped inverter

The block diagram of the DTC-CBSVPWM fed SPMSM using five-level diode clamped inverter is shown in Fig.2.The measured currents from the motor are transformed to $\alpha-\beta$ by using Clarke transformation. The voltage is estimated from the inverter switching state and the DC-link voltage in the $\alpha-\beta$ reference frame. From the transformed currents and the voltages the stator flux is estimated as

$\phi_{\alpha \beta}=\int\left(\mathrm{V}_{\alpha \beta}-\mathrm{R}_{\mathrm{s}} \mathrm{I}_{\alpha \beta}\right) \mathrm{dt}$

The magnitude of this estimated flux is compared with the required flux $\phi_{\mathrm{s}}{ }^{*}$. Then the torque is estimated as

$\mathrm{T}_{\mathrm{E}}=\frac{3}{2} \frac{\mathrm{p}}{2}\left(\lambda_{\mathrm{S} \alpha} \mathrm{I}_{\mathrm{S} \beta}-\lambda_{\mathrm{S} \beta} \mathrm{I}_{\mathrm{S} \alpha}\right)$

Which is compared with the required torque $\mathrm{T}^{*}$. Then the flux and torque errors go to flux-hysteresis and torque hysteresis comparators. The output of the comparators is given to carrier based space vector modulation from which the reference wave is generated similar to SVPWM. This reference wave is compared with the triangular waves same as pulse width modulation. The number of carrier waves required for five-level inverter is 4 . From this the pulses are generated for the five-level diode clamped inverter which have 24 IGBT's. The output of inverter goes to the surface-mounted PMSM drive whose speed, torques has to be controlled.

\section{CBSVPWM TECHNIQUE}

Carrier based space vector pulse width modulation is a novel voltage modulation technique called as 'unified voltage modulation' which is based on effective time concept. In this modulation the task is greatly simplified since the inverter output voltage is directly synthesized by the effective times. From the Fig.3 (a) the effective voltage is applied to the load side, when the each phase switching states changes from 0 to 1 at different time during one sampling interval. Let $\mathrm{T}_{\mathrm{s}}$ denotes the total sampling time and $T_{\text {eff }}$ is the effective time which is the difference between two switching time $T_{a s}, T_{b s}$. When $T_{b s}$ is greater than $T_{a s}$, then $T_{\text {eff }}$ have negative value and a negative voltage is applied to load side. For one leg operation the relation between voltage and times is give as

$\mathrm{V}_{\mathrm{as}}: \mathrm{V}_{\mathrm{dc}}=\mathrm{T}_{\mathrm{as}}: \mathrm{T}_{\mathrm{s}}$
$\mathbf{T}_{\mathrm{as}}=\frac{\mathbf{T}_{\mathrm{s}}}{\mathrm{V}_{\mathrm{dc}}} * \mathbf{V}_{\mathrm{as}}$

Where $\mathrm{V}_{\mathrm{as}}$ is the equivalent phase- $\mathrm{A}$ voltage for the load side. This switching time can be negative as long as negative phase voltage is commanded. These times are known as imaginary switching times and the effective time can be obtained from the different values of each imaginary switching times.

$\mathbf{T}_{\text {eff }}=\mathbf{T}_{\mathrm{as}}-\mathbf{T}_{\mathrm{bs}}=\frac{\mathbf{T}_{\mathrm{s}}}{\mathrm{V}_{\mathrm{dc}}}\left(\mathbf{V}_{\mathrm{as}}-\mathbf{V}_{\mathrm{bs}}\right)$

The average values of the three-phase leg voltages over an interval $\Delta \mathrm{T} / 2$, in terms of the midpoint of the $\mathrm{DC}$ link is given as,

$\mathbf{V}_{\mathrm{as}}=\mathbf{V}_{\mathrm{dc}}\left(\frac{\mathrm{T}_{\mathrm{sv} 1}}{\Delta \mathrm{T} / 2}+\frac{\mathrm{T}_{\mathrm{sv} 2}}{\Delta \mathrm{T} / 2}\right)$

$\mathbf{V}_{\mathrm{bs}}=\mathbf{V}_{\mathrm{dc}}\left(-\frac{\mathrm{T}_{\mathrm{sv} 1}}{\Delta \mathrm{T} / \mathbf{2}}+\frac{\mathrm{T}_{\mathrm{sv} 2}}{\Delta \mathrm{T} / \mathbf{2}}\right)$

$\mathbf{V}_{\mathrm{cs}}=\mathbf{V}_{\mathrm{dc}}\left(-\frac{\mathrm{T}_{\mathrm{sv} 1}}{\Delta \mathrm{T} / 2}+\frac{\mathrm{T}_{\mathrm{sv} 2}}{\Delta \mathrm{T} / 2}\right)$

These average values of voltages can be expressed as

$\mathrm{V}_{\mathrm{as}}=\frac{\sqrt{3}}{2} \mathrm{~V}_{0}\left[\cos \left(\theta_{0}+\frac{\pi}{6}\right)+\cos \left(\theta_{0}-\frac{\pi}{2}\right)\right]$

$\mathrm{V}_{\mathrm{bs}}=\frac{\sqrt{3}}{2} \mathrm{~V}_{0}\left[-\cos \left(\theta_{0}+\frac{\pi}{6}\right)+\cos \left(\theta_{0}-\frac{\pi}{2}\right)\right]$

$\mathrm{V}_{\mathrm{cs}}=\frac{\sqrt{3}}{2} \mathrm{~V}_{0}\left[-\cos \left(\theta_{0}+\frac{\pi}{6}\right)+\cos \left(\theta_{0}-\frac{\pi}{2}\right)\right]$

The maximum value of $\mathrm{V}_{0}$ is expressed as $\mathrm{V}_{0}=\mathrm{MV}_{\mathrm{dc}}$ where $0 \leq \mathrm{M} \leq 2 / \sqrt{3}$. Therefore the line-to-DC midpoint voltages can be written as

$\mathrm{V}_{\mathrm{as}}=\frac{\sqrt{3}}{2} \mathrm{MV}_{\mathrm{dc}}\left[\cos \left(\theta_{0}-\frac{\pi}{6}\right)\right]$

$\mathrm{V}_{\mathrm{bs}}=\frac{\sqrt{3}}{2} \mathrm{MV}_{\mathrm{dc}}\left[\cos \left(\theta_{0}-\frac{2 \pi}{3}\right)\right]$

$\mathrm{V}_{\mathrm{cs}}=\frac{\sqrt{3}}{2} \mathrm{MV}_{\mathrm{dc}}\left[\cos \left(\theta_{0}+\frac{5 \pi}{6}\right)\right]$

For the period $0 \leq \theta_{0} \leq \pi / 3$

The reference waveforms can be generated by adding a continuously varying offset voltage to the set of three phase voltage references which centers their envelope around zero at all times. 
The common offset voltage is given as

$\mathrm{V}_{\mathrm{off}}=\frac{\max \left(\mathrm{V}_{\mathrm{as}}^{*}, \mathrm{~V}_{\mathrm{bS}}^{*}, \mathrm{~V}_{\mathrm{CS}}^{*}\right)+\min \left(\left(\mathrm{V}_{\mathrm{as}}^{*}, \mathrm{~V}_{\mathrm{bS}}^{*}, \mathrm{~V}_{\mathrm{cS}}^{*}\right)\right.}{2}$

An additional common mode voltage which correctly positions the first and last switching transitions in each switching period can be given as

$\mathrm{V}_{\mathrm{off}}^{\prime}=\frac{\mathrm{V}_{\mathrm{dc}}}{\mathrm{N}-1}-\frac{\max \left(\mathrm{V}_{\mathrm{as}}^{*}, \mathrm{~V}_{\mathrm{bs}}^{*}, \mathrm{~V}_{\mathrm{cs}}^{*}\right)+\min \left(\left(\mathrm{V}_{\mathrm{as}}^{*}, \mathrm{~V}_{\mathrm{bs}}^{*}, \mathrm{~V}_{\mathrm{cs}}^{*}\right)\right.}{2}$

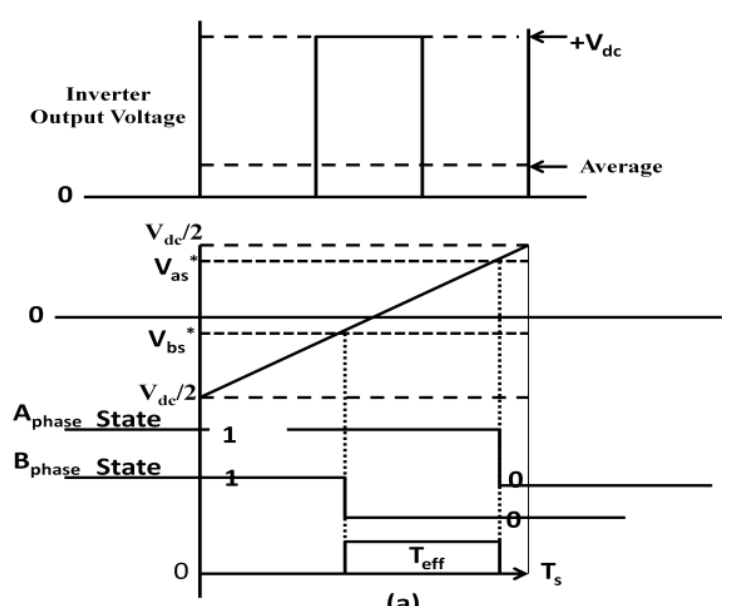

(a)

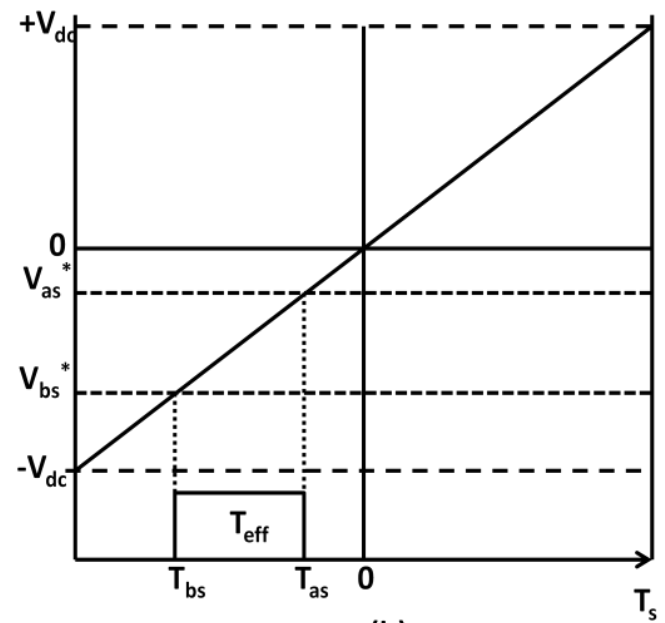

(b)

Fig.3 (a) Relationship between the effective time and the outputvoltage (b) Extended concept for effective time

Therefore, from the effective time relocation algorithm, full active voltage can be applied to the load like the space voltage vector PWM. If $\mathrm{V}^{*}$ is the reference voltage vector of SVPWM, then this can be represented by the two nearest active vectors as

$\mathbf{V}^{*}=\frac{T_{1} \cdot V_{n}+T_{2} \cdot V_{n+1}}{T_{s}}$

$\mathrm{V}_{\mathrm{as}}^{*}=\mathrm{V}_{\mathrm{ds}}^{*}$

$\mathrm{V}_{\mathrm{bs}}^{*}=-\frac{1}{2} \mathrm{~V}_{\mathrm{ds}}^{*}+\frac{\sqrt{3}}{2} \mathrm{~V}_{\mathrm{qs}}^{*}$

$\mathrm{V}_{\mathrm{cs}}^{*}=-\frac{1}{2} \mathrm{~V}_{\mathrm{ds}}^{*}-\frac{\sqrt{3}}{2} \mathrm{~V}_{\mathrm{qs}}^{*}$

If the zero voltage time is symmetrically distributed in one sampling period whole modulation task for SVPWM is accomplished by the proposed algorithm as shown in Fig.4 (b) To relocate the effective times at the centre of the sampling interval, a simple sorting algorithm is used to find out the minimum value and the maximum value among three imaginary switching times. So, the time shifting value $T_{\text {offset }}$ is

$\mathrm{T}_{\text {offset }}=\frac{1}{2} \mathrm{~T}_{0}-\mathrm{T}_{\min }$

$\mathrm{T}_{\mathrm{eff}}=\mathrm{T}_{\max }-\mathrm{T}_{\min }$

$\mathrm{T}_{0}=\mathrm{T}_{\mathrm{s}}-\mathrm{T}_{\mathrm{eff}}$

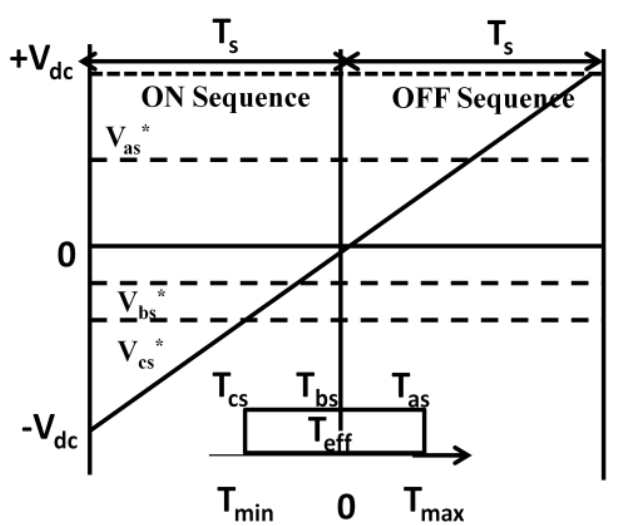

(a)

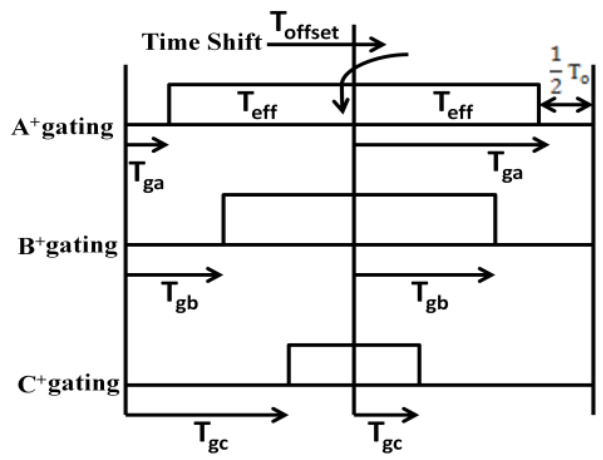

(b)

Fig.4 (a) Relationship between the effective time and the output voltage, (b) CBSVPWM gating generation

\section{FIVE-LEVEL DCML INVERTER}

Fig.5 shows the five-level diode clamped inverter fed to SPMSM drive, where only one DC source $V_{d}$ is needed. Four capacitors are used to split the DC voltage. The inverter leg $\mathrm{A}$ is composed of eight active switches $S_{1}, S_{2}, S_{3}, S_{4}, S_{1}, S_{2}{ }^{\prime}, S_{3}$ and $S_{4}{ }^{\prime}$ with eight anti-parallel diodes $\mathrm{D}_{1}$ to $\mathrm{D}_{8}$. The switches are employed with 24 IGBT's .Switching states for five-level inverter are shown in Tab. 1. For one leg operation of phase-A, for five-level diode clamped inverter, to have an output voltage of $\mathrm{V}_{\mathrm{dc}} / 2$ the switches $\mathrm{S}_{1}, \mathrm{~S}_{2}, \mathrm{~S}_{3}, \mathrm{~S}_{4}$, should conduct ,to have $\mathrm{V}_{\mathrm{dc}} / 4$ voltage, the switches $\mathrm{S}_{2}, \mathrm{~S}_{3}, \mathrm{~S}_{4}, \mathrm{~S}_{1}$ should conduct, to have zero voltage the switches $\mathrm{S}_{3}, \mathrm{~S}_{4}, \mathrm{~S}_{1}, \mathrm{~S}_{2}$ should conduct, to have $-\mathrm{V}_{\mathrm{dc}} / 4$ the switches $\mathrm{S}_{4}, \mathrm{~S}_{1}, \mathrm{~S}_{2}, \mathrm{~S}_{3}$ should conduct and to have $-\mathrm{V}_{\mathrm{dc}} / 2$ the switches $\mathrm{S}_{1}, \mathrm{~S}_{2}, \mathrm{~S}_{3}, \mathrm{~S}_{4}$ ' should conduct. For each voltage level four switches should conduct at a time. The maximum output voltage in the output is half of the DC. 


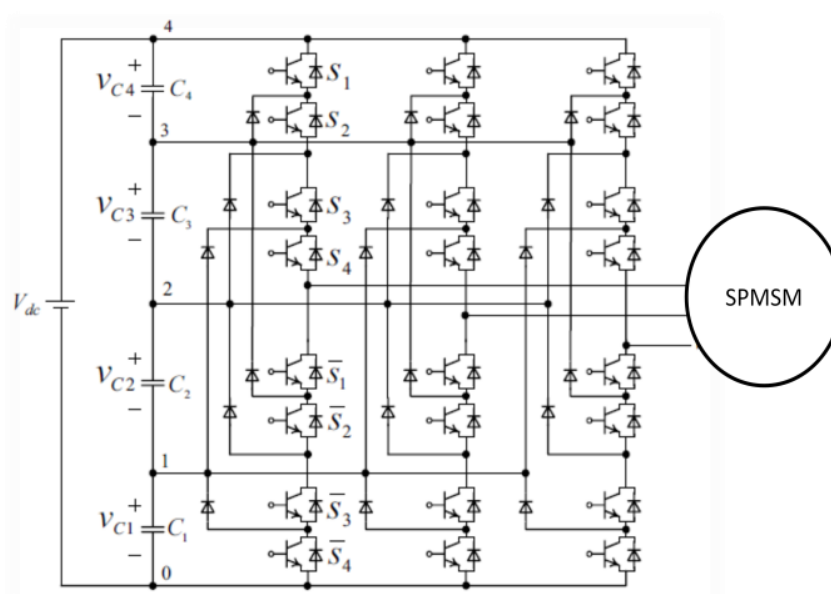

Fig.5 Five-level diode clamped inverter fed SPMSM

Table 1. Switching states of five-level diode clamped inverter

\begin{tabular}{|c|c|c|c|c|c|c|c|c|}
\hline \multirow{2}{*}{$\begin{array}{c}\text { Output } \\
\text { Voltag } \\
\mathbf{e}\end{array}$} & \multicolumn{10}{|c|}{ Switching Sequence } \\
\cline { 2 - 10 } & $\mathrm{S}_{1}$ & $\mathrm{~S}_{2}$ & $\mathrm{~S}_{3}$ & $\mathrm{~S}_{4}$ & $\mathrm{~S}_{1}$ & $\mathrm{~S}_{2}{ }^{\prime}$ & $\mathrm{S}_{3}{ }^{\prime}$ & $\mathrm{S}_{4}$ \\
\hline $\mathbf{V}_{\mathbf{d c}} / \mathbf{2}$ & 1 & 1 & 1 & 1 & 0 & 0 & 0 & 0 \\
\hline $\mathbf{V}_{\mathbf{d c}} / \mathbf{4}$ & 0 & 1 & 1 & 1 & 1 & 0 & 0 & 0 \\
\hline
\end{tabular}

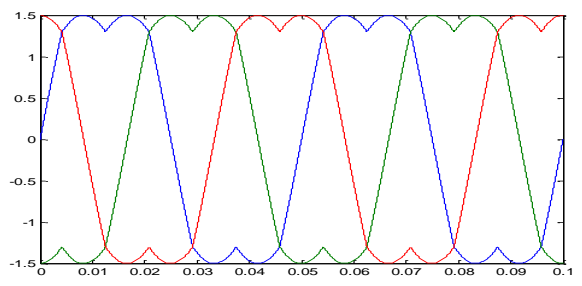

Fig.6 (a) Reference waveform of CBSVPWM

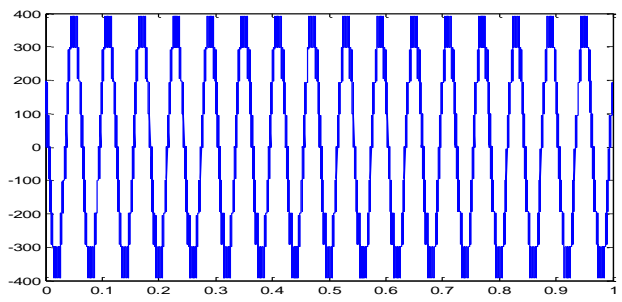

Fig.7 (a) Output Voltage waveform using FOC

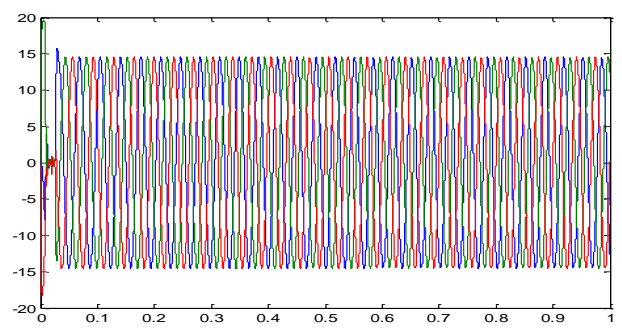

\begin{tabular}{|c|c|c|c|c|c|c|c|c|}
\hline $\mathbf{0}$ & 0 & 0 & 1 & 1 & 1 & 1 & 0 & 0 \\
\hline$-\mathbf{V}_{\text {dd }} \mathbf{4}$ & 0 & 0 & 0 & 1 & 1 & 1 & 1 & 0 \\
\hline$-\mathbf{V}_{\text {dc }} / \mathbf{2}$ & 0 & 0 & 0 & 0 & 1 & 1 & 1 & 1 \\
\hline
\end{tabular}

\section{SIMULATION RESULTS}

The simulation analysis of the DTC-CBSVPWM fed SPMSM using five-level diode clamped IGBT inverter system is investigated. The control scheme applied for the electrical drive is direct torque control. The modulation techniques used is CBSVPWM. The system used, was investigated for steady and transient state response. The output waveforms of three phase voltage and current for five-level inverter and the torque speed response of five level diode-clamped inverter fed SPMSM drive with DTC is estimated. The parameters used in this simulation are shown in below:

$\mathrm{L}_{\mathrm{d}}=0.0058$;

$\mathrm{L}_{\mathrm{q}}=0.0058$;

$\mathrm{R}=1.4$;

$\mathrm{PM}$ flux=0.1546;

$\mathrm{P}=6$;

$\mathrm{F}=0.000038818$

$\mathrm{J}=0.00176$;

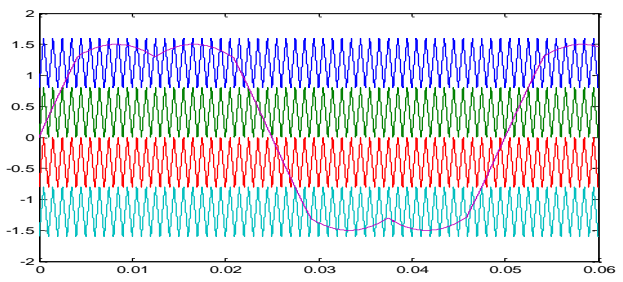

(b) Reference -carrier Waveform of CBSVPWM

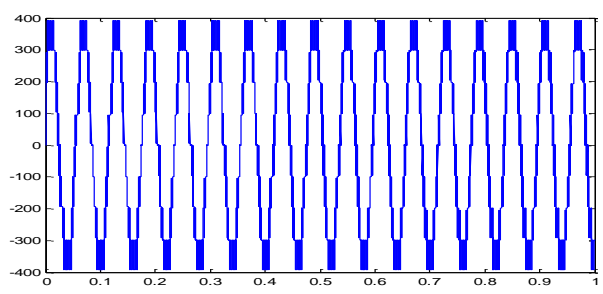

(b) Output voltage waveform using DTC-CBSVPWM

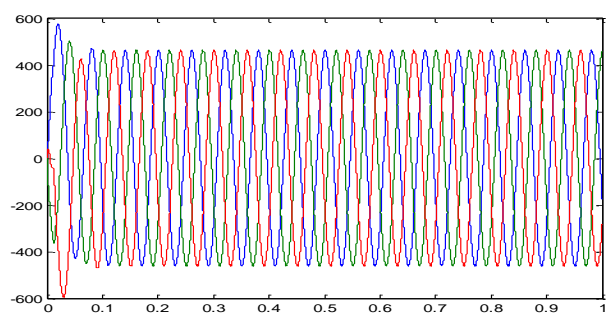

Fig.8 (a) Three-phase currents of SPMSM using FOC (b) Three-phase currents of SPMSM using DTC-CBSVPWM 


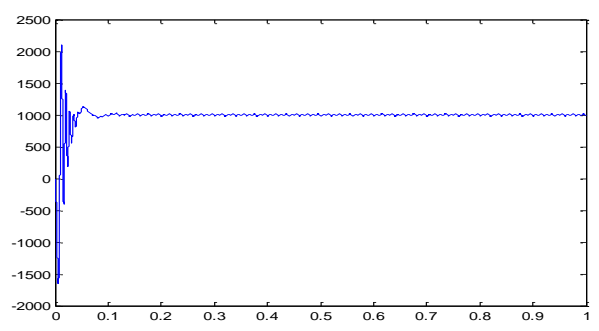

Fig.9 (a) Output speed response of SPMSM using FOC

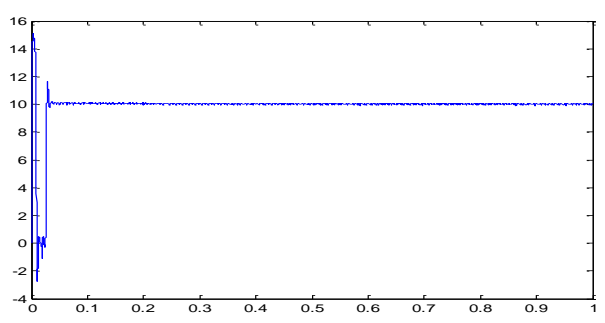

Fig.10 (a) Torque response of SPMSM using FOC

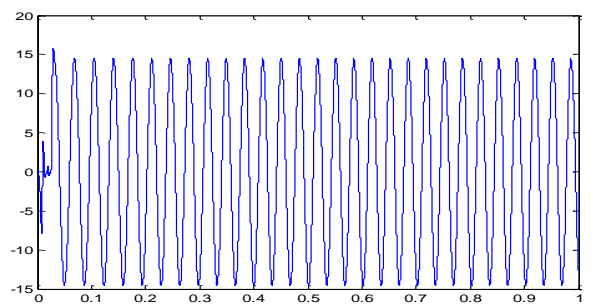

Fig.11 (a) Phase current of SPMSM using FOC

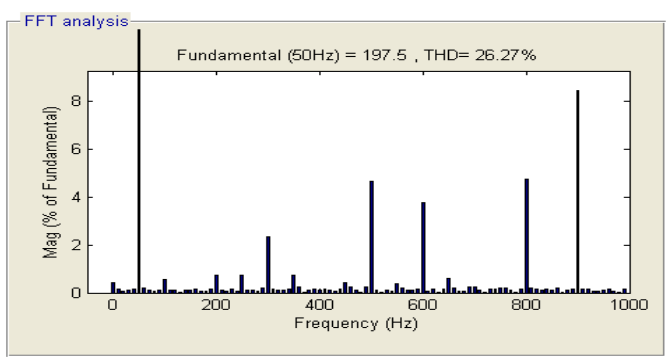

Fig.12 (a) THD of line voltage using FOC

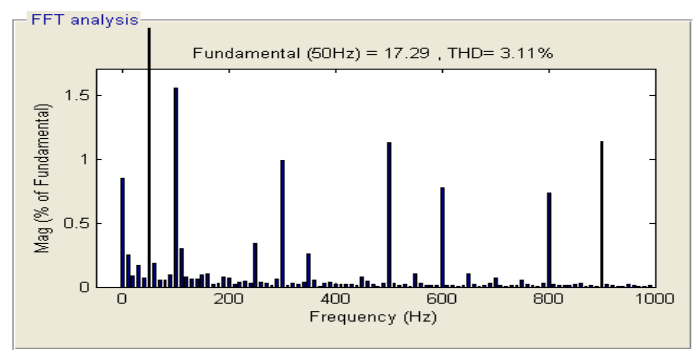

Fig.13 (a) THD of output line current using FOC

Fig.6 (a) shows the reference waveform of five-level inverter using CBSVPWM. Fig.6. (b) show the reference carrier waveform of five-level inverter using CBSVPWM. Fig.7. (a) \& (b) show the output voltage waveform of five-level diodeclamped inverter using FOC and DTC. Fig.8 (a) \& (b) show the output three-phase current of SPMSM using FOC and DTC. Fig. 9 (a) \& (b) show the output speed response of SPMSM using FOC \& DTC. Fig. 10(a) \& (b) show the output torque response

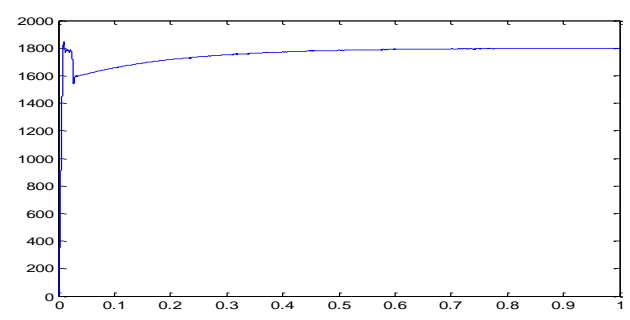

(b) Output speed response of SPMSM using DTC-CBSVPWM

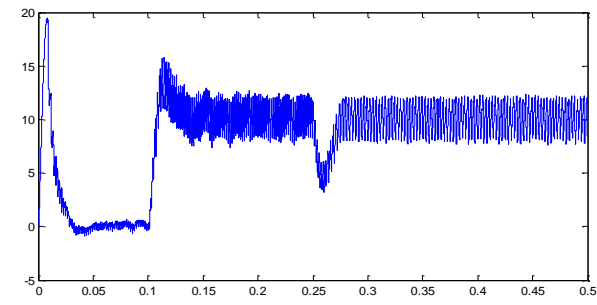

(b) Torque response of SPMSM using DTC-CBSVPWM

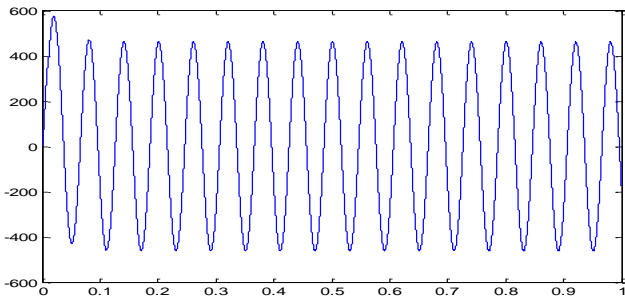

(b) Phase current of SPMSM using DTC-CBSVPWM

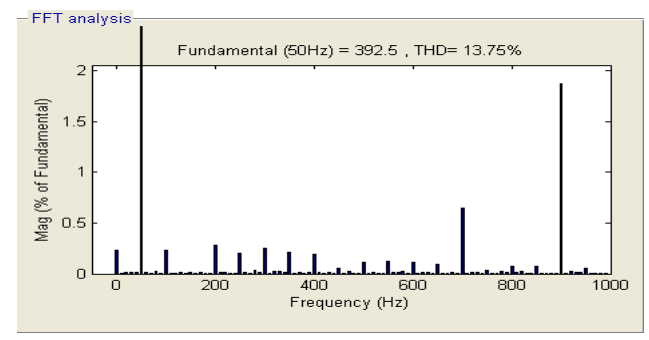

(b) THD of line voltage using DTC-CBSVPWM

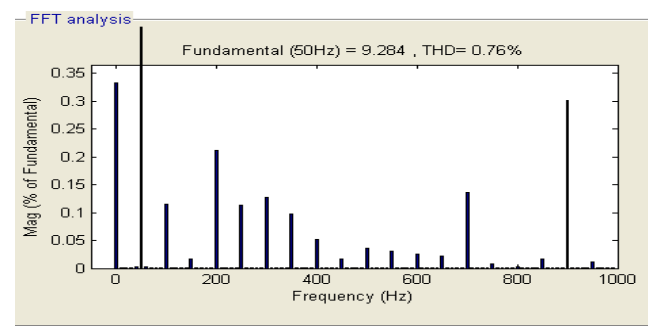

(b) THD of output line current using DTC-CBSVPWM

of SPMSM using FOC \& DTC. Fig.11 (a) \& (b) show the phase current of SPMSM using FOC \& DTC. Fig.12 (a) \& (b) show the THD of line voltage using FOC \& DTC. Fig.13 (a) \& (b) show the THD of line current using FOC \& DTC. From all the outputs it is clear that DTC-CBSVPWM controller gives better performance compared FOC. CBSVPWM technique can also be extended to n-level inverter as it is simple and easy to build. As the level increases the harmonics decreases, and better speed \& 
torque response can be obtained. Tab. 2 shows the THD of line voltage and line current for five-level diode clamped inverter fed SPMSM using FOC \& DTC. From this analysis we can conclude that direct torque control using CBSVPWM for SPMSM not only gives good dynamic performance but also reduces the total harmonic distortion of voltage and current when compared with field oriented control. Also CBSVPWM can be easily extended to n-level inverter without much complication.

Table.2 THD of Five-level DCML inverter output line voltage \& line current using FOC \& DTC-CBSVPWM

\begin{tabular}{|c|c|c|}
\hline THD & FOC & DTC \\
\hline Line voltage & 26.27 & 13.75 \\
\hline Line current & 3.11 & 0.76 \\
\hline
\end{tabular}

\section{CONCLUSION}

In this paper, the simulation model of direct torque control of five-level diode clamped inverter fed SPMSM drive using carrier based space vector pulse width modulation (CBSVPWM) technique has been studied. DTC gives fast and dynamic performance. It is similar to SVPWM but much simple, easy and the fastest method without much mathematical calculations like angle and sector determination. This method can be easily extended to n-level inverter. Therefore DTC-CBSVPWM gives simple, dynamic and fast response. The output voltage, current of the five-level diode clamped inverter and the speed, torque and the three-phase currents of surface-mounted PMSM have been plotted. The results are compared with the closed loop FOC. DTC-CBSVPWM gives better performance compared to conventional FOC.

\section{REFERENCES}

[1] R. Krishnan, "Permanent magnet synchronous and brushless dc motor drives", CRC Press, Taylor and Francis group, Newyork, 2010.

[2] Bimal K. Bose, "Power electronics and motor drives recent progress and perspective," IEEE Transactions on Industrial Electronics, 2009, vol. 56, no. 2, pp: 581-588.

[3] R. B. Sepe and J. H. Lang, "Real-time adaptive control of the permanent magnet synchronous motor," IEEE Transactions on Industrial Application, 1991, vol. 27, pp. 706-714.

[4] S. Morimoto, T. Ueno, and M. Sanada, "Effects and compensation of magnetic saturation in permanent magnet synchronous motor drives," IEEE, IAS Annual Meeting, 1993, vol. 3, no. 6, pp. 59-64.

[5] L. Zhong, M. F. Rahman, W. Y. Hu, and K. W. Lim, "Analysis of direct torque control in permanent magnet synchronous motor drives," IEEE Transaction on Power Electronics, 1997, vol. 12, pp. 528-536.

[6] Marian P. Kazmierkowski, Leopoldo G. Franquelo, Jose Rodriguez, Marcelo A. Perez, and Jose I. Leon, "Highperformance motor drives," IEEE Industrial Electronics Magazine, 2011,vol.5, no.3, pp: 6-26.

[7] Amor Khlaief, Moussa Bendjedia, Mohamed Boussak, "A nonlinear observer for high-performance sensorless speed control of Ipmsm drive," IEEE Transactions on Power Electronics, 2012,vol. 27, no.6, pp: 3028-3040.

[8] Zhao Kaiqi, "The study of improved pi method for pmsm vector control system based on svpwm," IEEE Conference Publication, 2011, pp: 1-4.

[9] Gilbert Hock Beng Foo, M. F. Rahman, "Direct torque control of an ipm-synchronous motor drive at very low speed using a sliding-mode stator flux observer," IEEE Transactions on Power Electronics, 2010.vol. 25, no. 4, pp: 933-942.

[10] Shanshan Wu, David Diaz Reigosa, Vuichi Shibukawa Michael A. Leetmaa, Robert D. Lorenz, and Vongdong Li, "Interior permanent-magnet synchronous motor design for improving self-sensing performance at very low speed," IEEE Transactions on Industry Applications, 2009,vol. 45, no. 6.pp:1939-1946.

[11] M. Nasiruddin, Tawfik S. Radwan, G. H. George, and M. Azizur Rahman, "Performance of current controllers for VSI-fed IPMSM drive," IEEE Transaction on Industry Applications, 2000,vol. 36, no. 6, pp: 1531-1538.

[12] L. Zhong, M. F. Rahman,W. Y. Hu, and K. W. Lim, "Analysis of direct torque control in permanent magnet synchronous motor drives," IEEE Transactions on Power Electronics, 1997,vol. 12, no. 3, pp: 528-536.

[13] Jose Rodriguez, Jih-Sheng Lai, and Fang Zheng Peng, "Multilevel inverters: A survey of topologies, controls, and applications,'IEEE Transactions on Industrial Electronics, 2002, vol. 49, no. 4, pp: 724-748

[14] Leopoldo G. Franquelo, Jose Rodriguez, Jose I. Leon, Samir Kouro, Ramon Portillo, and Maria A. M. Prats, "The age of multilevel converters arrives," IEEE Industrial Electronics Magazine, vol.2, no.2, pp: 28-39, 2008.

[15] L. M. Tolbert, F. Z. Peng, and T. Habetler, "Multilevel converters for large electric drives", IEEE Transactions on Industrial Application, vol.35, pp: 36-44, 1999.

[16] Jose Rodriguez, Steffen Bernet, Peter K. Steimer, Ignacio E. Lizama, "A survey on neutral-point-clamped inverter," IEEE Transactions on Industrial Electronics, vol.57, no.7, 2010.

[17] Hasegawa.K, Akagi.H, "Low-modulation-index operation of five-level diode-clamped pwm inverter with a dc-voltagebalancing circuit for a motor drive," IEEE Transaction on Power Electronics, vol.27.no.8, pp: 3495-3501, 2012.

[18] Ui-Min Choi, Hyun-Hee Lee, and Kyo-Beum Lee, "Simple neutral-point voltage control for three-level inverters using a discontinuous pulse width modulation, IEEE Transactions on Energy Conversion, vol.28, no.2, pp: 434-443,2013.

[19] Dae-woong Chung, Joohn-Sheok Kim and Seung-ki sul, "unified voltage modulation technique for real time threephase power conversion," IEEE Transaction,vol.34,n0.2,pp:374-380,1996.

[20] Xiao-ling Wen and Xiang-gen yin, "The unified pwm implementation method for three-phase inverters," IEEE Conference Publication, pp: 241-246, 2007.

[21] Jang-Hwan Kim, Seung-Ki Sul and Prasad N. Enjeti, "A carrier-based pwm method with optimal switching sequence for a multi-level four-leg VSI," IEEE Conference Publication,pp:99-105, 2005.

[22] Grahame Holmes Thomas A. Lipo, "Pulse width modulation for power converters principles and practice," IEEE Series On Power Engineering, A John Wiley \& Sons, Interscience Publication,2003. 


\section{AUTHORS PROFILE}

G. Sree Lakshmi was born in the year 1979 in Andhra Pradesh, India. She has received her B.Tech. Degree in Electrical \& Electronics Engineering from JNT University, Hyderabad, India in 2002, and M.Tech. Degree with Power Electronics \& Industrial Drives from JNT University, Hyderabad, India in 2007. She is presently working in the Department of Electrical \& Electronics Engineering, CVR College of Engineering, Hyderabad. Her areas of interest are Power Electronic Drives \& Simulation of Electrical Machines. She has published/presented 7 technical research papers in national and international conferences and journals.

S. Kamakshaiah was born in the year 1940 in Andhra Pradesh, India. He received BE (Hons) (Gold Medalist) at S. V. University in 1962, India. He received his ME (HVE) and PHD (Gold Medalist) from IISC, Bangalore, India. He worked as Professor and Head, Dept of EEE and also Chairman of Electrical science at JNT University Ananthapur. He won the 'Best Teacher Award' for the year 1997-98. He has around 40 IEEE publications. He is author of 10 text books in Electrical
Engineering. He has guided $10 \mathrm{Ph} . \mathrm{D}$ candidates and presently guiding $5 \mathrm{Ph}$.D. candidates. His areas of interest are Electrical Networks, Electrical Machines, HVDC, GIS, and Power Systems. He presented papers at various IEEE conferences at USA and Canada.

G. Tulasi Ram Das was born in the year 1960 in Hyderabad, Andhra Pradesh, India. He has received his B.Tech. degree in Electrical \& Electronics Engineering from J.N.T.U. College of Engineering, Hyderabad, India in 1983, M.E. degree with Industrial Drives \& Control from O.U. College of Engineering, Hyderabad, India in 1986 and received his Ph.D. degree from the Indian Institute of Technology, Madras, India in 1996. He is presently Honble Vice Chancellor Jawaharlal Nehru Technological University, Kakinada. His Research interests are Power Electronics; Industrial Drives \& FACTS Controllers. He has published/presented 115 technical research papers in national and international conferences and journals. He has 22 years of experience. He is a member in editorial board of three journals. He has guided 13 Ph.D. candidates and currently guiding 5 Ph.D. candidates. 